\title{
Factors Affecting Caesarean Labor in RSUD Lembang in 2017
}

\author{
Regina A.B. Pratiwi*, Rimonta F. Gunanegara**, July Ivone*** \\ *Faculty of Medicine Maranatha Christian University \\ **Department of Obstetric and Gynaecology \\ Faculty of Medicine Maranatha Christian University \\ ***Department of Public Health Faculty of Medicine Maranatha Christian University \\ Jl. Prof. drg. Suria Sumantri MPH No.65 Bandung 40164 Jawa Barat Indonesia \\ Email: julyivone@gmail.com
}

\begin{abstract}
Indonesian Maternal Mortality Ratio (MMR) based on the Survei Demografi Kesehatan Indonesia (SDKI) in 2012 is 356/100.000 live birth whereas the target of Sustainable Development Goals (SDG's 70/100,000 live birth by 2030. A decent labor assistance in both vaginal and sectio caesarean labor is necessary in reducing MMR. This study aimed to analyze the relationship between maternal age, parity and payment method with labor through caesarean section. This is an observational analytic study using cross sectional design. The data was obtained through secondary data from medical record. During 2017 there were 183 caesarean sections in RSUD Lembang as our research location. The data was analyzed univariately and bivariately by using Chi Square test $(\alpha=0.05)$. The results shows that factors associated with caesarean labor are maternal age $(p=0.032 ;$ OR $=4.617)$, parity $(p=0.035$; $O R=4.442$ ) and payment method ( $p=0.036$; $O R=4.417)$. It can be concluded that maternal age, parity and payment method affect caesarean labor.
\end{abstract}

Keywords: caesarean labor, caesarean section, age, parity, payment method 


\title{
Faktor - Faktor yang Memengaruhi Persalinan dengan Sectio Caesarea di RSUD Lembang pada tahun 2017
}

\author{
Regina A B Pratiwi*, Rimonta F. Gunanegara**, July Ivone ${ }^{* * *}$ \\ * Fakultas Kedokteran Universitas Kristen Maranatha \\ **Bagian Obstetri dan Ginekologi Fakultas Kedokteran Universitas Kristen Maranatha \\ ***Bagian Ilmu Kesehatan Masyarakat Fakultas Kedokteran Universitas Kristen Maranatha \\ Jl. Prof.Drg.Surya Sumantri, MPH No 65 Bandung 40164 Indonesia \\ Email : julyivone@gmail.com
}

\begin{abstract}
Abstrak
Angka Kematian Ibu (AKI) di Indonesia menurut Survei Demografi Kesehatan Indonesia (SDKI) tahun 2012 adalah 359/100.000 kelahiran hidup. Angka tersebut masih jauh dari target Sustainable Development Goals (SDG's) yaitu 70/100.000 kelahiran hidup di tahun 2030. Salah satu cara menurunkan AKI adalah pertolongan persalinan yang memadai baik secara per vaginam maupun Sectio Caesarea (SC). Tujuan penelitian ini untuk menganalisis hubungan antara usia ibu, paritas dan metode pembayaran dengan persalinan melalui SC menggunakan metode penelitian analitik observasional dengan desain cross sectional, menggunakan data sekunder dari rekam medis. Selama tahun 2017, terdapat 183 persalinan dengan SC di RSUD Lembang. Data dianalisis secara univariat dan bivariat menggunakan uji chi square $(\alpha=0,05)$. Dari hasil penelitian didapatkan faktor yang berhubungan dengan persalinan melalui SC adalah usia ibu ( $\mathrm{p}=0,032$; $\mathrm{OR}=4,617)$, paritas $(\mathrm{p}=0,035 ; \mathrm{OR}=4,442)$ dan metode pembayaran $(\mathrm{p}=0,036$; $\mathrm{OR}=4,417)$. Dapat disimpulkan bahwa usia ibu, paritas dan metode pembayaran memengaruhi persalinan dengan SC.
\end{abstract}

Kata Kunci: sectio caesarea, operasi caesar, usia, paritas, metode pembayaran 


\section{Pendahuluan}

Angka Kematian Ibu (AKI) adalah jumlah kematian ibu karena kehamilan, persalinan dan masa nifas pada setiap 1000 kelahiran hidup dalam satu wilayah pada kurun waktu tertentu. ${ }^{1}$ Berdasarkan Survei Demografi Kesehatan Indonesia (SDKI) tahun 2012, terjadi penurunan AKI di Indonesia pada tahun 1991 yaitu 390/100.000 kelahiran hidup dan pada tahun 2012 menjadi 359/100.000. Jumlah kelahiran hidup, masih jauh dari target Sustainable Development Goals (SDGs) ketiga yang bertujuan untuk mengurangi AKI secara global menjadi kurang dari 70/100.000 kelahiran hidup pada tahun 2030.,3 Tujuan yang ingin dicapai dengan penurunan AKI adalah tercapainya kesejahteraan rakyat dan pembangunan masyarakat dunia termasuk Indonesia., ${ }^{3,4}$ Pertolongan persalinan baik secara spontan maupun Sectio Caesarea (SC) yang memadai dapat membantu menurunkan AKI dan meningkatkan kesejahteraan ibu hamil.

Sectio Caesarea (SC) didefinisikan sebagai kelahiran fetus melalui laparatomi lalu histeretomi. Tindakan SC dilakukan karena adanya komplikasi dan penyulit yang dapat menyebabkan kematian bagi ibu. Indikasi SC secara klinis dibagi menjadi 3, yaitu indikasi ibu, utero-plasental dan janin. ${ }^{5}$ Panggul dan rahim pada ibu dengan usia $\leq 20$ tahun belum berkembang dengan baik sehingga dapat menjadi penyulit persalinan. Selain itu risiko kematian akibat persalinan pada wanita usia $<20$ dan $>35$ tahun juga 3 kali lebih tinggi dari kelompok usia reproduksi sehat (21-35 tahun). ${ }^{6}$ Paritas adalah jumlah seluruh persalinan yang telah dialami oleh seorang ibu. Paritas 1-3 adalah paritas paling aman ditinjau dari sudut perdarahan pascasalin yang dapat mengakibatkan kematian maternal. Paritas $>3$ memiliki angka kejadian perdarahan pascasalin yang lebih tinggi. ${ }^{7}$

Angka persalinan SC di Jawa Barat menurut RISKESDAS tahun 2013 adalah sekitar 8,7\%. ${ }^{8}$ RSUD Lembang adalah Rumah Sakit kelas D Pratama yang dimiliki dan dikelola oleh Pemerintah Daerah Kabupaten Bandung Barat, berlokasi di Kecamatan Lembang, Kabupaten Bandung Barat, Provinsi Jawa Barat. Rumah sakit ini berdiri sejak tahun 2015 dan merupakan rumah sakit yang menerima metode pembayaran melalui jaminan pemerintah seperti BPJS dan Jampersal. ${ }^{9}$

Pada persalinan dengan SC dibutuhkan perawatan yang lebih lama dibandingkan persalinan per vaginam, keadaan ini turut memberikan konsekuensi pada besarnya biaya pelayanan kesehatan yang lebih tinggi. ${ }^{10}$ Hal ini akan menambah beban anggaran kesehatan khususnya masyarakat miskin yang biaya perawatannya dibebankan pada negara. Disamping itu, pemerintah juga menyediakan asuransi kesehatan untuk seluruh masyarakat Indonesia, di antaranya BPJS dan Jampersal yang menganggung biaya tindakan persalinan melalui SC. ${ }^{11,12}$ 
Data - data inilah yang memungkinkan tingginya metode pembayaran tindakan SC melalui BPJS ataupun Jampersal di RSUD Lembang. Berdasarkan latar belakang di atas, maka perlu peneliti berminat untuk meneliti faktor-faktor yang mempengaruhi persalinan dengan sectio caesarea (SC) di RSUD Lembang periode 1 Januari - 31 Desember 2017.

\section{Metode}

Penelitian ini bersifat analitik observasional dengan desain cross sectional dengan bahan penelitian berupa data sekunder dari rekam medik pasien rawat inap yang melakukan persalinan di RSUD Lembang periode 1 Januari - 31 Desember 2017. Variabel dalam penelitian ini terdiri dari variabel independen berupa usia ibu, paritas serta metode pembayaran dan variabel dependen berupa Sectio Caesarea (SC).

Pengambilan data dilakukan secara whole sample kemudian dianalisis secara univariat dan dilanjutkan dengan analisis secara bivariat menggunakan uji chi square $(\alpha=0,05)$. Penelitian dengan menggunakan data rekam medis ini telah disetujui oleh Komisi Etik Penelitian Fakultas Kedokteran Universitas Kristen Maranatha - Rumah Sakit Immanuel dengan Surat Keputusan No:058/KEP/III/2018.

\section{Hasil}

Dari hasil pengumpulan data dari rekam medik pasien melahirkan di Bagian Ilmu Obstetri dan Ginekologi RSUD Lembang Kabupaten Bandung Barat menyatakan didapatkan 437 ibu melakukan persalinan selama periode 1 Januari-31 Desember 2017.

Tabel 1 Distribusi Berdasarkan Metode Persalinan

\begin{tabular}{lcc}
\hline \multicolumn{1}{c}{ Metode Persalinan } & Jumlah & Persentase (\%) \\
\hline Persalinan dengan SC & 183 & 41,9 \\
Persalinan spontan & 254 & 58,1 \\
\hline Total & 437 & 100 \\
\hline
\end{tabular}

Dari 437 data rekam medik yang dikumpulkan didapatkan sebanyak $183(41,9 \%)$ pasien melakukan persalinan dengan SC dan sebanyak $254(58,1 \%)$ pasien melahirkan spontan.

Tabel 2 Distribusi Pasien dengan SC berdasarkan Indikasi

\begin{tabular}{cccc}
\hline & Indikasi & Jumlah & Persentase (\%) \\
\hline Maternal & 102 & 55,7 \\
Utero - plasental & 10 & 5,5 \\
Fetus & 71 & 38,8 \\
\hline \multicolumn{1}{c}{ Total } & 183 & 100 \\
\hline
\end{tabular}


Dari 183 data rekam medis pasien yang melahirkan dengan SC, didapatkan jumlah paling banyak adalah SC atas indikasi maternal atau ibu, yaitu 102 (55,7\%) pasien, 71 (38,8\%) pasien yang melahirkan dengan SC atas indikasi fetus dan terendah didapat pada pasien yang melakukan SC atas indikasi utero-plasental, yaitu $10(5,5 \%)$ pasien.

Indikasi dari SC sebenarnya relatif dan bergantung pada diagnosis dari tenaga medis bidang obstetrik. Lebih dari 85\% SC dilakukan karena 4 alasan, yaitu riwayat SC sebelumnya, distosia, gawat janin, atau letak janin yang abnormal. ${ }^{13}$

Tabel 3 Distribusi Indikasi Klinis Pasien yang Melakukan SC

\begin{tabular}{lcc}
\hline \multicolumn{1}{c}{ Indikasi } & Jumlah & Persentase (\%) \\
\hline Riwayat SC sebelumnya & 43 & 23,5 \\
Letak janin abnormal & 39 & 21,3 \\
Penyakit maternal & 28 & 15,3 \\
Gawat janin & 19 & 10,4 \\
Disporposi sefalopelvik & 17 & 9,3 \\
Lain - Lain & 37 & 20,2 \\
\hline \multicolumn{1}{c}{ Total } & 183 & 100 \\
\hline
\end{tabular}

Sesuai tabel 3, pada penelitian ini didapatkan lima indikasi klinis dilakukannya SC yang terbanyak adalah karena riwayat SC sebelumnya yaitu 43 pasien $(23,5 \%)$, diikuti oleh letak janin yang abnormal sebanyak 39 pasien $(21,3 \%)$, penyakit maternal sebanyak 28 pasien $(15,3 \%)$, gawat janin sebanyak 19 pasien $(10,4 \%)$ dan disproporsi sefalopelvik 17 pasien $(9,3 \%)$.

Tabel 4 Analisis Hubungan Usia Ibu dengan SC

\begin{tabular}{lccccc}
\hline \multirow{2}{*}{ Usia } & \multicolumn{2}{c}{ Jenis Persalinan } & \multirow{2}{*}{ Total } & OR & P value \\
\cline { 2 - 3 } & Spontan & SC & & \\
\hline $\begin{array}{l}\text { Berisiko Rendah }(21 \\
-35 \text { tahun })\end{array}$ & $154(60,6 \%)$ & $130(71 \%)$ & $284(65 \%)$ & 4,617 & 0,032 \\
$\begin{array}{l}\text { Berisiko Tinggi }(<21 \\
\text { tahun dan }>35 \\
\text { tahun) }\end{array}$ & $100(39,4 \%)$ & $53(29 \%)$ & $153(35 \%)$ & & \\
\hline \multicolumn{1}{c}{ Total } & & & & & \\
\hline
\end{tabular}

Pada tabel 4 diperoleh jumlah pasien yang melakukan persalinan dengan usia yang berisiko rendah adalah 284 (65\%) pasien dan berisiko tinggi untuk SC adalah 153 (35\%) pasien. Bila dilihat dari jenis persalinannya, $154(60,6 \%)$ pasien yang melahirkan spontan memiliki usia yang berisiko rendah dan $100(39,4 \%)$ pasien memiliki usia yang berisiko tinggi. Sedangkan untuk persalinan dengan SC, 130 (71\%) pasien memiliki usia yang berisiko rendah dan 153 $(35 \%)$ pasien memiliki usia yang berisiko tinggi 
Didapatkan hasil analisis uji statistik hubungan usia ibu dengan SC dengan nilai $\mathrm{p}=0,032$ dengan nilai $\mathrm{OR}=4,617$ yang berarti terdapat hubungan yang bermakna antara usia ibu dengan persalinan melalui SC dan pasien yang memiliki usia yang berisiko tinggi untuk SC memiliki risiko 4,617 kali untuk melahirkan melalui SC dibandingkan dengan pasien yang memiliki usia berisiko rendah untuk SC.

Tabel 5 Analisis Hubungan Paritas dengan SC

\begin{tabular}{lccccc}
\hline \multirow{2}{*}{ Paritas } & \multicolumn{2}{c}{ Jenis Persalinan } & \multirow{2}{*}{ Total } & OR & P value \\
\cline { 2 - 3 } & Spontan & SC & & \\
\hline $\begin{array}{l}\text { Berisiko Rendah } \\
\text { (paritas 1 }-3)\end{array}$ & $137(53,9 \%)$ & $118(64,5 \%)$ & $225(58,4 \%)$ & 4,442 & 0,035 \\
$\begin{array}{l}\text { Berisiko Tinggi } \\
(\text { paritas 0 dan }>3)\end{array}$ & $117(46,1)$ & $65(35,5 \%)$ & $182(41,6 \%)$ & & \\
\hline \multicolumn{1}{c}{ Total } & $254(100 \%)$ & $183(100 \%)$ & $437(100 \%)$ & \\
\hline
\end{tabular}

Dari hasil penelitian, pada tabel 5 terlihat bahwa $255(58,4 \%)$ pasien melakukan persalinan dengan paritas yang berisiko rendah dan $182(41,6 \%)$ pasien memiliki paritas yang berisiko tinggi untuk SC. Pasien yang melakukan persalinan spontan terdiri dari 137 (53,9\%) pasien yang memiliki paritas berisiko rendah untuk SC dan $117(64,1 \%)$ pasien yang paritasnya berisiko tinggi. Pada pasien yang melakukan persalinan dengan SC, didapatkan $118(64,5 \%)$ pasien yang memiliki paritas yang berisiko tinggi untuk SC dan $65(35,5 \%)$ pasien dengan paritas berisiko rendah.

Hasil analisis uji statistik antara persalinan melalui SC dengan paritas menunjukkan terdapat hubungan yang bermakna antara persalinan melalui SC dengan paritas ibu, ditunjukkan dengan nilai $\mathrm{p}=0,035$ dan $\mathrm{OR}=4,442$. Artinya ibu dengan paritas berisiko tinggi 4,442 kali lebih berisiko untuk bersalin melalui SC dibandingkan dengan ibu yang jumlah paritasnya berisiko rendah untuk SC.

Tabel 6 Analisis Hubungan Metode Pembayaran dengan SC

\begin{tabular}{lccccc}
\hline Metode & \multicolumn{2}{c}{ Jenis Persalinan } & \multirow{2}{*}{ Total } & \multirow{2}{*}{ OR } & \multirow{2}{*}{ P value } \\
\cline { 2 - 3 } Pembayaran & Spontan & SC & & & \\
\cline { 2 - 4 } Mandiri & $30(11,8 \%)$ & $10(5,5 \%)$ & $40(9,2 \%)$ & 4,417 & 0,036 \\
BPJS/Jampersal & $224(88,2 \%)$ & $173(94,5 \%)$ & $397(90,8 \%)$ & & \\
\hline \multicolumn{1}{c}{ Total } & $254(100 \%)$ & $183(100 \%)$ & $437(100 \%)$ & & \\
\hline
\end{tabular}

Pada tabel 6 didapatkan 397 (90,8\%) pasien menggunakan metode pembayaran untuk persalinan menggunakan BPJS/Jampersal, sedangkan yang membayar secara mandiri hanya 40 orang $(9,2 \%)$. Bila dilihat dari jenis persalinan, pada persalinan normal terdapat $30(11,8 \%)$ pasien yang melakukan pembayaran secara mandiri dan $224(88,2 \%)$ pasien yang menggunakan 


\section{Research Article}

BPJS/Jampersal. Pada persalinan dengan SC, 10 (5,5\%) pasien melakukan pembayaran mandiri dan 173 (94,5\%) pasien melakukan pembayaran dengan BPJS/Jampersal.

Didapatkan nilai $\mathrm{p}=0,036$ dengan $\mathrm{OR}=4,417$ pada hasil analisis uji statistik antara hubungan persalinan melalui SC dengan metode pembayaran, yang artinya terdapat hubungan yang bermakna antara persalinan melalui SC dengan metode pembayaran, pasien yang membayar melalui BPJS/Jampersal 4,417 kali lebih mungkin untuk mengambil keputusan bersalin melalui SC.

\section{Diskusi}

Pada penelitian ini didapatkan adanya hubungan yang bermakna antara persalinan melalui SC dengan usia ibu dan paritas. Hal ini didukung oleh penelitian Mohammed yang menyatakan bahwa peningkatan usia $(\mathrm{p}=<0.05)$ dan paritas $(\mathrm{p}=<0.02)$ berhubungan dengan peningkatan SC dan penelitian Isti et al yang menyatakan terdapat hubungan antara usia $(\mathrm{p}=0.02)$ dan paritas $(0.006)$ dengan SC. ${ }^{7,14}$

Berdasarkan penelitian ini, usia ibu ( $\leq 20$ tahun atau $\geq 35$ tahun) lebih berisiko terhadap tindakan SC dibandingkan dengan ibu yang berusia 21-34 tahun. Panggul dan rahim pada ibu dengan usia usia $\leq 20$ belum berkembang dengan baik sehingga dapat menjadi penyulit persalinan. Selain itu risiko kematian pada wanita usia $<20$ dan $>35$ tahun juga 3 kali lebih tinggi dari kelompok usia reproduksi sehat (21-35 tahun). ${ }^{6}$

Paritas 1-3 adalah paritas paling aman ditinjau dari sudut perdarahan paska persalinan yang mengakibatkan kematian maternal. Paritas 0 dan $>3$ memiliki angka kejadian perdarahan paska persalinan yang lebih tinggi. ${ }^{7}$ Pada paritas 0 , Pada ibu dengan paritas 0 , kemungkinan terjadinanya kelainan dan komplikasi cukup besar baik pada kekuatan his (power), jalan lahir (passage) dan kondisi janin (passenger). Hal ini disebabkan tidak adanya pengalaman melahirkan dan dapat juga dikarenakan informasi yang kurang tentang persalinan yang dapat memengaruhi proses persalinan. ${ }^{15}$

Ibu dengan usia dan paritas tinggi cenderung memiliki disfungsi pola persalinan dan risiko yang lebih tinggi untuk mengalami persalinan pervaginam yang kurang baik. Otot normal pada dinding myometrium tergantikan oleh kolagen dan terjadi peningkatan lesi sklerotik. Keadaan ini menyebabkan penurunan perfusi utero - plasental, penurunan oksigenasi fetal dan perburukan fungsi myometrium. Hipoperfusi dan hipofungsi myometrium merupakan factor penting yang menyebabkan keadaan janin tidak mendukung kehamilan, plasenta previa dan distosia yang merupakan indikasi dari SC. ${ }^{14}$ 
Pada penelitian ini didapatkan adanya hubungan yang bermakna antara persalinan melalui SC dengan metode pembayaran. Hal ini didukung oleh penelitian Marice dan Lelly yang menyatakan terdapat hubungan antara metode pembayaran (asuransi dan pribadi) dengan persalinan melalui SC $(\mathrm{p}=0,000) .{ }^{10}$

Badan Penyelenggara Jaminan Sosial (BPJS) kesehatan dan Jaminan Persalinan (Jampersal) adalah program Jaminan Kesehatan Nasional (JKN-KIS) yang diselenggarakan oleh negara. BPJS kesehatan memiliki tujuan meningkatkan pelayanan kesehatan bagi seluruh pesertanya yang telah membayar iuran dan menanggung biaya tindakan medis spesialistik sesuai dengan indikasi medis termasuk persalinan dengan SC. ${ }^{11}$ Jampersal diselenggarakan dalam upaya menurunkan AKI dan Angka Kematian Bayi (AKB) dimana pesertanya adalah ibu hamil, ibu bersalin dan ibu nifas yang belum memiliki jaminan pembiayaan persalinan yang menanggung biaya pelayanan persalinan dengan tindakan emergensi komprehensif seperti persalinan dengan $\mathrm{SC} .^{12}$

Pada tabel 6 dapat dilihat tingginya persentase pasien yang menggunakan metode pembayaran dengan BPJS/Jampersal baik pada persalinan spontan maupun persalinan dengan SC. Hal ini mungkin disebabkan karena banyaknya jumlah penduduk miskin disertai pendapatan perkapita yang rendah dari masyarakat Kabupaten Bandung Barat yang termasuk dalam cakupan wilayah pelayanan RSUD Lembang. Data Badan Pusat Statistik pada tahun 2016 menyatakan bahwa jumlah penduduk miskin di Kabupaten Bandung Barat adalah 192.480 jiwa (11,7\% dari total penduduk) dengan pendapatan perkapita Rp. 298.823/bulan dan Indeks Keparahan Kemiskinan 0,51, dimana angka ini cukup tinggi bila dibandingkan dengan kota Bandung $(0,18){ }^{16-18}$

Indeks Keparahan Kemiskinan adalah Indeks yang memberikan informasi mengenai gambaran penyebaran pengeluaran di antara penduduk miskin, dimana semakin tinggi nilai indeks, semakin tinggi ketimpangan pengeluaran di antara penduduk miskin. ${ }^{19}$ Data - data tersebut memungkinkan untuk dijadikan alasan tingginya penggunaan metode pembayaran persalinan dengan SC menggunakan BPJS/Jampersal.

\section{Simpulan}

Berdasarkan hasil penelitian data rekam medik pasien yang melakukan persalinan di RSUD Lembang periode 1 Januari - 31 Desember 2017, disimpulkan bahwa: (1) Jumlah persalinan dengan SC di RSUD Lembang sebanyak 183 dengan persentase 41,9\%, (2) Indikasi melakukan persalinan dengan SC di RSUD Lembang adalah 55,7\% atas indikasi ibu, 5,5\% atas 


\section{Research Article}

indikasi utero-plasental dan 38,8\% atas indikasi janin, (3) Usia, paritas dan metode pembayaran memengaruhi persalinan dengan SC.

\section{Daftar Pustaka}

1. Dinas Kesehatan Jawa Barat. Dinas Keshatan Jawa Barat. Profil Kesehatan Indonesia. 2012:1-138. doi:0178-0000-15-104-H01-P

2. Kementerian Kesehatan RI. Infodatin Pusat Data dan Informasi Kementerian Kesehatan RI. Penyebab Kematian Ibu. 2014:8.

3. WHO. UN Sustainable Development Summit 2015. [Cited 2018 Mar 4] Available from: http://www.who.int/mediacentre/events/meetings/2015/un-sustainable-development-summit/en/.

4. Kementerian Kesehatan Republik Indonesia. Profil Kesehatan Indonesia.; 2016.

5. Norwitz E, Schorge J. Obstetrics and Gynecology at a Glance, Fourth Edition. Wiley-Blackwell Publication. Boston; 2013.

6. Kementrian Kesehatan RI. Pedoman Pemantauan Wilayah Setempat Kesehatan Ibu Dan Anak (PWSKIA). Jakarta; 2010.

7. Mulyawati I, Azam M, Nur Aggraini Ningrum D. Faktor Tindakan Persalinan Operasi Sectio Cesarea. Jurnal Kesehatan Masyarakat. 2011;7(1):14-21.

8. Badan Penelitian dan Pengembangan Kesehatan. Riset Kesehatan Dasar (RISKESDAS) 2013. Lap Nas 2013. 2013:1-384. doi:1 Desember 2013

9. RSUD Lembang. Profil RSUD Lembang. [Cited 2018 April 23]. Available from: http://rsudlembang.blogspot.com/2017/01/profil-rumah-sakit.html.

10. Sihombing M, Andayasari L. Determinan Persalinan Seksio Sesarea Pasien Kelas Tiga di Dua Rumah Sakit di Jakarta Tahun 2011. Badan Penelitian dan Pengembangan Kesehatan, Kementrian Kesehatan RI. 2015; 7(3):173-181.

11.BPJS Kesehatan. Seputar BPJS Kesehatan, 2013:46. [Cited 2018 April 3]. Available from: https://bpjs-kesehatan.go.id/bpjs/dmdocuments/eac4e7a830f58b4ade926754f74b6caf.pdf.

12. Kementerian Kesehatan Republik Indonesia. Informasi Jampersal. 2011.

13. Cunningham FG, Leveno KJ, Bloom SL, Spong CY, Dashe JS, Hoffman BL, et al. : OBSTETRICS. 24th ed. McGraw-Hill Education; 2014.

14. Hiasat MS. The Impact of Maternal Age And Parity On The Cesarean Section RatE. Journal of Research in Medical Science. 2015; 12(1): 30-34.

15.Wirakusuma F. Kehamilan dan Persalinan dengan Parut Uterus. In: Ilmu Kebidanan Sarwono Prawirohardjo. 4th ed. Jakarta: Yayasan Bina Pustaka Sarwono Prawirohardjo; 2010:614-619.

16.Badan Pusat Statistik Provinsi Jawa Barat. Jumlah Penduduk Miskin (ribu jiwa) Menurut Kabupaten/Kota di Jawa Barat, 2002-2016. BPS jabar. [Cited 2018 April 3]. Available from: https://jabar.bps.go.id/statictable/2016/10/13/121/jumlah-penduduk-miskin-menurut-kabupaten-kotadi-jawa-barat-ribu-orang-2002-2016.html.

17. Badan Pusat Statistik Provinsi Jawa Barat. Garis Kemiskinan Menurut Kabupaten/Kota di Jawa Barat (Rp/kapita/bulan), 2005-2016. [Cited 2018 April 3]. Available from: https://jabar.bps.go.id/statictable/2016/10/13/123/garis-kemiskinan-menurut-kabupaten-kota-di-jawabarat-rp-kapita-bulan-2005-2016.html.

18. Badan Pusat Statistik Provinsi Jawa Barat. Indeks Keparahan Kemiskinan Menurut Kabupaten/Kota di Jawa Barat, 2005-2016. BPS jabar. [Cited 2018 April 3]. Available from: https://jabar.bps.go.id/statictable/2016/10/13/125/indeks-keparahan-kemiskinan-menurut-kabupatenkota-di-jawa-barat-2005-2016.html.

19. Badan Pusat Statistik. Indeks Keparahan Kemiskinan. Badan Pusat Statistik. [Published 2018; Cited 2018 April 3]. Available from: http://sirusa.bps.go.id/index.php?r=indikator/view\&id=20. 